\title{
Strategies Used by Teachers of Mathematics in the Implementation of Tasks
}

\author{
Jakeline Amparo Villota Enríquez ${ }^{1}$, Heriberto González Valencia ${ }^{1}$ \& Andréia María Pereira de Oliveira ${ }^{2}$ \\ ${ }^{1}$ Education Faculty, Santiago de Cali University, Cali, Valle, Colombia \\ ${ }^{2}$ Universidade Federal da Bahia, Colombia \\ Correspondence: Heriberto González Valencia, Education Faculty, Santiago de Cali University, Cali, Valle, \\ Colombia. Tel: 57-313-720-7896. E-mail: hery77@hotmail.com
}

\author{
Received: February 4, $2018 \quad$ Accepted: February 28, 2018 Online Published: April 30, 2018 \\ doi:10.5539/mas.v12n5p114 URL: https://doi.org/10.5539/mas.v12n5p114
}

The research is financed by Universidad Santiago de Cali.

\begin{abstract}
This article identifies and describes the teaching strategies used by mathematic teachers in implementing tasks. The context of this study was the classroom of three mathematic teachers at elementary and secondary education. This study is framed as a qualitative approach, using observation and interview as the tool for data collection. The results showed that there are varieties of teaching strategies used by the teachers in the implementation of mathematical tasks, classified in the following categories: Pre-instructional, co-instructional and post-instructional proposed by Diaz and Hernandez (2010).
\end{abstract}

Keywords: teaching strategies, mathematical tasks and teachers.

\section{Introduction}

\subsection{Introduce the Problem}

This article focuses on the subject of teaching strategies used by mathematic teachers. The interest in dealing with this topic is due to the importance they have in the pedagogical practice of the teacher and education (Kohler, 2005). In this way, strategies are seen as a powerful tool in the teaching and learning process.

Starting from the premise that relating teaching strategies with the practice of the teacher is not an easy task, we can admit that the teacher does not teach abstract bodies but individual persons where learning is not a subject (Quintero, 2008). In other words, the relationship of teaching strategies within the pedagogical practice of the teacher is a task that must be done with great care at the time of use.

In this way, identifying the different strategies used by the teacher in a given task proposed to the students, lead us to observe, perceive and reflect on what each of the strategies consists of when implementing them. In this sense, more than identifying the teaching strategies, it is also of great importance to know what each of them consists of; that is, their description is vital in order to generate an adequate and efficient use of them in the student's learning process.

In addition, it should be noted that in this study the time of use and presentation addressed by the teacher of each teaching strategy in the implementation of tasks is essential as this leads to an a priori classification of them, which is proposed by Díaz and Hernández (2010).

Consequently, the objective of this article is to identify and describe the strategies used by mathematic teachers in the implementation of tasks. Thus, we initially identify the teaching strategies and then present their respective description, to later classify them. Next, the consistency of this study is presented in detail, in which it is approached: Some conceptions about different terms, context, methodology, presentation of the data, discussion and final considerations.

\subsection{Teaching Strategies}

The teaching strategies are tools that teachers have had to strengthen the achievement of the objectives set within any activity provided to their students; that is, teaching strategies are tools that the teacher uses to achieve the 
objectives, mainly the intellectual development of the student, as mentioned by Kohler (2005, p.33), "... teaching strategies are the basic tools of teachers to achieve their main objective: The intellectual development of the learner ".

In this article, we will define teaching strategies as those orientations that the teacher gives to students in order to promote learning; it is about the orientations that the teacher provides to the students with the purpose of developing in them different capacities for the interpretation of the information related to a certain task. In this case particularly, the teaching strategies refer to the set of guidelines that the teacher gives the students in order to promote the development of the mathematical task.

In this way, the mathematical task according to (Margolinas, 2013; Burkhardt; Swan, 2013) cited by Costa (2015) is considered as that segment of activities addressed in the classroom where students are invited to solve problems, develop mathematical concepts ideas and strategies to perform procedures and thus offer opportunities for learning Mathematics.

In other words, these tasks contain certain mathematical concepts that are related to the curricular contents because when it comes to developing concepts, there is a strong link with the different topics that the teacher must address; that is, the curricular contents.

In this sense, we recognize that there is a strong relationship between curricular content and teaching strategies, since this is where both elements were measured, as Camilloni (1998, p.186) cited by Anijovich and Mora (2009, p.4):

"It is essential, for the teacher, to pay attention not only to the topics that must be included in the programs and that should be addressed in class, but also, and simultaneously, in the manner in which it can be considered more convenient for those topics to be worked on by the students. The relationship between themes and the way to approach them is so strong that it can be argued that both themes and didactic treatment strategies are inseparable."

Under these perspectives, Kohler (2005) and Camilloni (1998) complement each other; since they recognize the relationship that exists between the teaching strategies and the curricular contents addressed by the teacher, without losing sight of the fact that there are different knowledge that help in the construction of the strategies (Askew and Canty, 2013; Barbosa and Oliveira, 2013; Kullberg, Runesson, Jönköping, 2013, Omoregie, 2013, Margonilas, 2013). Thus, this relationship is inseparable, so we cannot try to isolate or separate them, thus becoming complementary elements that play a transcendental role in the student's learning process, strengthening the development of the different contents.

Consequently, in Mathematics, this correspondence is fundamental for student learning, as stated by Gonzáles (2009, p.523):

"The way in which it is taught in the classrooms of basic education makes abstract contents prevail, without support in resources that allow building knowledge, going from concrete and semi-concrete representations of mathematical ideas and concepts, to synthesis activities that facilitate the abstraction and generalization of the mathematical contents of the level. The way Mathematics is taught is as important as the content."

In this way, teaching strategies can be implemented by the teacher before, during or after addressing specific curricular content. In this sense, teaching strategies can be classified taking into account the time of use and presentation of the teachers to achieve their objectives within the tasks.

Indeed, the authors Díaz and Hernández (2010) classify the teaching strategies according to the time of use and their respective presentation, thus generating three categories called: Pre-instructional, co-instructional and postinstructional. 


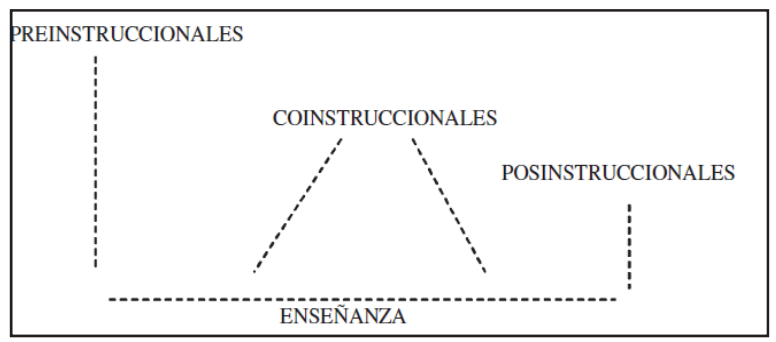

Figure 1. Types of teaching strategies, according to the moment of their presentation in a teaching sequence.

Source: Díaz and Hernández (2010) (Spanish version)

Pre-instructional strategies are those that start a certain task, with the purpose of preparing and alerting the student in relation to what and how to learn; that is, they try to generate the activation of relevant prior knowledge and experiences, which allow them to be placed in the context of appropriate learning. Consequently, the preinstructional strategies within this study are all those that the teacher uses before initiating the development of the content of the mathematical task.

The co-instructional strategies support the development of curricular contents during the teaching process; that is to say, they cover orientations related to the conceptualization of contents, structure and interrelationships of contents, maintaining the attention and motivation of the student among others. This implies that co-instructional teaching strategies are those that the teacher uses during the development of the task in order to strengthen the development of it.

The post-instructional strategies are presented after the student has done the content that has to be learned, allowing him to form an integrative and critical view of the material; that is, these strategies are used by the teacher after the student has explored and developed the math task.

Thus, the classification of the strategies addressed by Díaz and Hernández (2010) strengthens and tries to favor the pertinent use that the teacher can give to each of them in the learning process of their students; in other words, it allows the teacher to visualize the strategies in order to implement them adequately in their pedagogical practice.

In this sense, the classification of teaching strategies, beyond providing an organizational scheme, tries to give the teacher a wider view on their use, with the purpose of being able to implement them in the different activities, such as, for example, mathematical tasks. Consequently, in the following sections we present a set of strategies used by three mathematic teachers at the time of implementing exploratory tasks, which will be initially identified, described and then categorized according to the time and presentation.

Below, the context where this study was developed and the methodology are presented. In this section, we will discuss information about the training and pedagogical practice of the teachers participating in this research, related to the school context. Regarding the methodology, we will explain the instruments used for the production of the data.

\section{Context and Methodology of Study}

The data of this article was collected in each of the classrooms (eliminate- rooms) of the mathematic teachers: Cecília, Giovanna and Rivaldo, who were invited to take part in this study. Consequently, the teachers implemented three mathematical tasks; that is, each (eliminate -of the) teachers implemented a task within the classroom.

Thus, in the following chart, we will show the respective information of teachers Cecília, Giovanna and Rivaldo regarding their academic training, work experience, mathematical task implemented and objective of the task, in order to present a broader picture regarding the context.

Chart 1. Information of the teachers participating in the study.

\begin{tabular}{ccccc}
\hline Teacher & $\begin{array}{c}\text { Academic } \\
\text { training }\end{array}$ & $\begin{array}{c}\text { Work } \\
\text { experience }\end{array}$ & Applied task & $\begin{array}{c}\text { Objective of the } \\
\text { task }\end{array}$ \\
\hline Cecília & $\begin{array}{c}\text { Bachelor of } \\
\text { Science and }\end{array}$ & 22 years & $\begin{array}{c}\text { Proportional } \\
\text { greatness }\end{array}$ & $\begin{array}{c}\text { To recognize and } \\
\text { relate the greatness } \\
\text { through flat } \\
\text { geometry. }\end{array}$ \\
& & & & \\
\end{tabular}




\begin{tabular}{ccccc}
\hline Giovanna & $\begin{array}{c}\text { Economy with } \\
\text { complementati } \\
\text { on in } \\
\text { Mathematics }\end{array}$ & 16 years & Percentage & $\begin{array}{c}\text { To study the } \\
\text { percentage } \\
\text { concept and its } \\
\text { applications. }\end{array}$ \\
\hline Rivaldo & $\begin{array}{c}\text { Bachelor in } \\
\text { Mathematic }\end{array}$ & 10 years & $\begin{array}{c}\text { Localization } \\
\text { of rational } \\
\text { numbers }\end{array}$ & $\begin{array}{c}\text { To locate the } \\
\text { rational numbers } \\
\text { on the number } \\
\text { line. }\end{array}$ \\
\hline
\end{tabular}

Source: Villota (2016)

On the other hand, as we stated above, the data obtained in this research was collected in the classrooms where the teachers implemented the mathematical tasks. The interest of this study was initiated thanks to our participation in the collaborative group "Observatory of mathematical education (OME)", in which the members build educational curricular materials, particularly mathematical tasks.

Thus, the objective of this OME collaborative group is to outline task proposals for the teaching of topics foreseen in the program of the discipline of mathematics, inspiring changes in pedagogical practices. These tasks are implemented in the classrooms of the teachers who participate in the group, so that the experience could be documented. Under this perspective, we perceive important to relate the teaching strategies with the mathematical tasks elaborated in this group.

Subsequently, we built the study proposal, which objective was to identify and describe teaching strategies used by mathematic teachers in the implementation of tasks. After constructing the proposal, we socialized it within the OME collaborative group in order to invite the teachers to be part of it; proposal that was well received, Cecília, Giovanna and Rivaldo of elementary and secondary education accepted to participate in this study.

In relation to the above, and taking into account the objective of this study that consisted in identifying and describing the teaching strategies that the mathematic teachers used in the implementation of the tasks; the method used in this research is qualitative, according to Creswell (2007), since it constitutes an exploratory, descriptive and comprehensive study; that is, it is fundamentally interpretive.

Consequently, qualitative research is characterized by the possibility of using different data collection instruments that depend on the research question to be answered and to be investigated Denzin and Lincol (2005). In this study, the collection of data was done through observation and interview. Mainly, the observation consisted of: 1) Filming the classes in which the mathematic teachers implemented the tasks and 2) Making different annotations about the strategies used. Therefore, the observation was the basis for conducting the interviews, based on the studies of Reitano (2006); that is, through memories, stimulating the subject.

According to Reitano (2006), an interview of this type allows the individual to relive original situations with clarity and precision when subjected to stimuli; that is, this data production instrument was intended to revive in the memory of the teachers some moments recorded in the videos and annotations to obtain data in a more detailed way about different aspects that could be missed in several situations. These interviews were done to each of the teachers after having observed the films and annotations; by means of a series of questions regarding the strategies used, reminding them of moments through these records.

In relation to the above, the data analysis of this study was done based on the Grounded Theory of Charmaz (2009), which contains a guide to be able to encode and then categorize the data, after the transcriptions made. In this sense, the coding included a process of selection, classification and systematization of the transcribed data; that is, the data was refined to strengthen this process and thus establish comparisons and then assign them codes taking into account the theory.

\section{Presentation of the Data}

In this section, the situations that are shown were structured around the words and actions of the teachers Cecília, Rivaldo and Giovanna, respectively, during the development of each mathematical task, which were developed in different classrooms. In addition to the words collected in the observation process, the interviews conducted with the teachers after the completion of the task were used as a consultation, with the purpose of complementing the information of the observation data.

In this way, some of the elements used in the transcription of the data are treated in the works of Brum-de-Paula and Espinar (2002). However, the others are adapted to support transcription. Among these elements we have 
several codes such as: 1) the information inside brackets that indicate an action of the participants or explanations of their way of speaking. 2) The symbol "..." to show an idea or word.

In addition to these codes, each line of the transcript was enumerated from (1), precisely to facilitate localization when references are made to it. However, before each numbering, we assign a letter to identify when they are reported on the line, that is, the letter $\mathrm{O}$ is assigned to the lines recorded during the observation of the teachers in the development of tasks. Thus, the first line of each transcription episode is initiated by $(\mathrm{O} 1)$; the second by $(\mathrm{O} 2)$; and so on.

The situations were constructed from what was considered important in the observation and expressed suggestively. In this way, in this article the situations are categorized into three sets, where the teaching strategies used by teachers are identified, described and classified: Cecília, Rivaldo and Giovanna, shown in chronological order.

In this sense, each set of situations represents a category where it was constructed, taking into account the moment of use and the presentation of the teaching strategy, as suggested by Díaz and Hernández (2010). In this case, we classify the teaching strategies used by the teachers: Cecília, Rivaldo and Giovanna in three sets of situations where the teaching strategies are pre-instructional, co-instructional and post-instructional.

Thus, the set of situations 1 refers to teaching strategies that teachers used as opening; that is, pre-instructional strategies. The set of situations 2 constitutes the teaching strategies used during the task activities; that is, coinstructional strategies. And, the set of situations 3 presents the set of teaching strategies that were implemented for the closure of the task; that is, the post-instructional strategies.

\subsection{Set of Situations 1: Pre-Instructional Teaching Strategies}

In this "set of situations 1", we will locate the teaching strategies that the teachers implemented at the time of opening the task; that is, through certain situations that arose before the task was developed. Initially, the teachers: Cecília, Rivaldo and Giovanna used as teaching strategy the organization of students in small groups, which consisted in forming small groups of students; promoting the interaction among them, as illustrated below:

Table 1. Organization of students in small groups

(O1) Cecília: "Good morning everyone. We are going to work in pairs and we will try to develop the next task. You can choose who to work with".

(O2) Rivaldo: "Now! Please, work in groups of five students to complete the task. You can freely choose who you want to work with".

(O3) Giovanna: "Please, work in groups of five students to explore the task. You can choose your classmates, but you can only work five students per group".

Source: Villota (2016)

It is visualized in $(\mathrm{O} 1),(\mathrm{O} 2)$ and $(\mathrm{O} 3)$ that each teacher organizes the students in small groups; varying the number of students regarding the organization of the groups. In addition it is observed that each teacher gave the student the freedom to perform the development of the task with the classmate they wanted to work with. Then, all the teachers, in their respective classroom, distribute the tasks to the different groups formed. Subsequently, they use the teaching strategy called, state the objective of the task, where they express aloud the objective of the task, as presented below:

Table 2. State the purpose of the task

(O4) Cecília: "We will study in this task, the use of contents of geometry, the relationship between greatness. So, the objective of our task is not to work or to know what is right or to calculate the area, but to study the relationship of greatness".

(O5) Rivaldo: "The task we will perform involves the exploration of the location of those numbers on the number line [rational numbers]. The objective of the task is that." (O6) Giovanna: "Today, our goal is to study the percentage concept and its applications in solving problems". 
In this way, it is observed in (O4), (O5) and (O6) that each teacher expresses the objective of the respective task; For example, teacher Cecília tell the students that the objective of the task is to relate the greatness. As for, teacher Rivaldo expresses that in this task, the students will explore the location of the rational numbers on the line, that being the objective. While the teacher Giovanna announces to the students that the objective of the task, is to study the percentage concept and its applications.

Consequently, the teachers: Cecília, Rivaldo and Giovanna feel motivated to read the task; that is, they use shared reading as a teaching strategy, which consisted in carrying out a shared reading of the task, inviting each student to pay attention to it, as shown in the following situation:

Table 3. Reading the shared task

(O7) Cecília: "We are going to read the task. Please follow the reading. Initially, you will build on the graph paper three rectangles with height of the same measurement and the bases with different measurements. Then, you will answer questions like: What was the base measure? What area do you have? In the second question, on the same graph paper, you are going to build a rectangle that has the measure of the base and the height chosen by you. For example; 2 and 3 . And then, you must double the height measurement on the rectangle and choose the area of it. For example; I can choose the area 10 . We can start!"

(O8) Rivaldo: Follow the reading of the task. Today our class will be about rational numbers. The task we will perform involves the exploration of the location of those numbers on the number line. Let's start! Look at the number line and then answer the questions below. Are you looking at the number line?

(O9) Students: Yes

(O10) Rivaldo: Below in letter a) locate the following numbers on the number line above. [List of rational numbers]

$$
\frac{2}{10} ;-1,5 ;-\frac{4}{2} ; 0,2 ; \frac{1}{4} ; \frac{5}{5} ; 3+\frac{1}{4} ;-\frac{8}{4} ; 2,9 ;-\frac{7}{3}
$$

Has anyone already found the first number?

(O11) Students: No

(O12) Rivaldo: So let's [...].

(O13) Giovanna: Girls please stop what you are doing! And follow the reading of the task, we will work on the percentage concept.

"... Joao, Paulo, Ana and Maria inherit 4 plots of the same (eliminate-time and) size, (eliminate- each one of them with a plot of land) and they decided to farm part of the land. Joao farmed two quarters of land, Ana farmed two fifths of the land, Paulo farmed four tenths of the land and Maria farmed six twentieths of the land. Question 1: Who of the four, use most of the land? Explain your reasoning. Question 2: Suppose that each individual takes the land in 100 equal parts. Represent in the box below the part of the land used by each one..."

Source: Villota (2016)

Thus, it is observed in $(\mathrm{O} 7),(\mathrm{O} 8), \ldots,(\mathrm{O} 13)$ that the teacher invites student to read the task in order to capture the attention of the students, asking them to leave any other activity they are doing at that moment. However, teacher Rivaldo in $(\mathrm{O} 8), \ldots,(\mathrm{O} 12)$ tries to establish a dialogue with the students through the invitation to read the mathematical task proposed to them.

In this way, we ended the "set of situations 1" where we located through specific situations that arose in the implementation of mathematical tasks, the different teaching strategies, allowing us to describe them and then classify them. In "this set of situations 1", we place the pre-instructional teaching strategies, used as an opening by all teachers, which is made up of the strategies mentioned and described above. Below we present the set of situations 2.

\subsection{Set of Situations 2: Co-Instructional Teaching Strategies}

In this "set of situations 2", we find the teaching strategies that teachers: Cecília, Rivaldo and Giovanna 
implemented during the development of the task, which will be shown below.

The teaching strategy called, use of alternate questions, was used by the teachers: Cecília, Rivaldo and Giovanna, and consisted in asking different questions to the students in order that they respond; and, so to observe how they were reasoning, to then guide them and help them perceive, reflect and build the solution of the task. This strategy motivated the students to scrutinize the previous concepts, to make the construction of the task. This teaching strategy is shown below:

Table 4. Use of alternate questions

(O1) Student: All numbers are even.

(O2) Cecília: And why are they even?

(O3) Student: Because it ends in zero.

(O4) Cecília: When is a number even?

(O5) Student: When it ends in 0, 2, 4, 6 and 8.

(O6) Cecília: But, what other property does an even number have?

(O7) Student: it can be a multiple of two.

(O8) Cecília: But could something happen with division?

(O9) Student: Division! I think it could not.

(O10) Cecília: If I have an even number, can I divide it?

(O11) Student: For example, 8 area, I can divide it by 2 equals to 4 .

(O12) Cecília: Very good!

Source: Villota (2016)

The previous situation shows the use of the teaching strategy addressed by teacher Cecília. However, teachers Rivaldo and Giovanna implemented this strategy analogously; that is, teacher Giovanna asked alternate questions related to the percentage issue and teacher Rivaldo made reference to the location of rational numbers on the number line.

In this way, it is observed in $(\mathrm{O} 1)$ and $(\mathrm{O} 2)$, that the affirmations lead to questions that stimulate the student to answer in the immediacy of what he is thinking, making use of the previous concepts that he already knows, as it is visualized in (O3), generating, between affirmations and questions, the possibility for the student, little by little, to construct his reasoning, as shown in $(\mathrm{O} 3),(\mathrm{O} 5),(\mathrm{O} 7),(\mathrm{O} 9),(011)$. However, in $(\mathrm{O} 9)$ and $(\mathrm{O} 10)$, it is perceived that through this construction of argument, doubts arise, where the presence of the teacher is crucial to guide the student and thus reach the construction of reason, as seen in (O11). ) and (O12).

Next, the teaching strategy called, promoting interaction among students, is presented; which was used by all teachers and consisted of each teacher letting their students interact with each other, in order to share ideas for the construction of the task solution; generating dialogue, debates, discussions and reflections. In the following situation we can observe the use of this teaching strategy:

Table 5. Promote student interaction

(O13) Student 1: Do we have to draw a rectangle with the same height?

(O14) Student 2: Yes,

(O15) Student 2: Can we choose the height and the base?

(O16) Student 1: Not always. In the first question?

(O17) Student 2: I choose height 3, what base do you want to choose?

(O18) Student 1: Base 3. Now, what do we do?

(O19) Student 2: Find the area: multiplying the base by the height.

(O20) Student 1: The area is 9.

(O21) Student 2: Very good!

Source: Villota (2016)

Therefore, interaction among students strengthens the sharing of ideas, questions, arguments and others as we observe in (O13), (O14), (O15), (O16), (O17), (O18), (O19), (O20) and (O21), in which dialogue is fundamental to generate the interaction of students. 
Subsequently, another teaching strategy called, analogies related to daily life, was implemented by teacher Giovanna and teacher Rivaldo where it is about relating events of the student's daily life with the mathematical concepts that are addressed in the task; for example, the use of money, evaluation grades, among others; that is, the use of analogies related abstract knowledge with some applications located within the context of the student's daily life. Thus, in the following determined situation it is observed how this teaching strategy is used:

Table 6. Analogies related to daily life

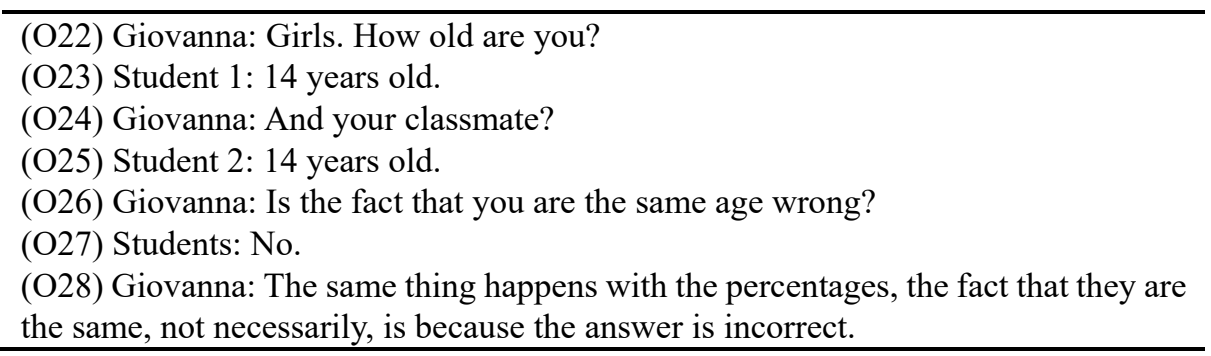

Source: Villota (2016)

The situation where teacher Giovanna uses this teaching strategy was chosen at random, given that teacher Rivaldo implemented this strategy analogously; he used the grades that the students obtained in the exams to relate them to the concepts addressed in the task.

The previous situation shows us in $(\mathrm{O} 22),(\mathrm{O} 23),(\mathrm{O} 24)$ and $(\mathrm{O} 25)$ that an analogy related to the students' age is used, which leads them to reflect, visualize and affirm their answers or the opposite, that they rethink their reasoning is wrong, as indicated in $(\mathrm{O} 26),(\mathrm{O} 27)$ and $(\mathrm{O} 28)$.

Next, teacher Giovanna and teacher Rivaldo used another teaching strategy called, legitimizing the answers presented by the students; it consisted, initially, when teachers legitimated directly the different answers given by the students, so that later they rectified them, as it is presented next:

Table 7. Legitimize the answers presented by the students.

(O29) Student: I think $3+\frac{1}{4}$ is a single number, but it's also a sum. I think my answer

is wrong!

(O30) Rivaldo: You have to locate a number only on the line.

(O31) student: I mean, do I have to add 3 plus $\frac{1}{4}$ ? (it was disorganized, spaces)

(O32) Rivaldo: Yes, but remember that it is a just number.

(O33) Student: That is, the sum would give 3 as 25. Is that it?

(O34) Rivaldo: Yes!

(O35) Student: And that is number I have to locate?

(O36) Rivaldo: Yes

Source: Villota (2016)

It is important to note that the situation in which teacher Rivaldo used this teaching strategy was chosen at random. Teacher Giovanna also implemented this strategy analogously; that is to say, it legitimized in several moments of the development of the task several of the answers presented by the students, related to the thematic of percentage.

In this way, we can visualize in (O29) that the student doubts his reasoning so he needs the teacher's help to reaffirm his answer; and, it is from the legitimization, as observed in $(\mathrm{O} 30),(\mathrm{O} 31),(\mathrm{O} 32),(\mathrm{O} 33)$, that he manages to see that his way of reasoning is totally correct, thus getting to be sure of the adequacy of the construction of his 
rationales, as shown in (O34), (O35) and (O36).

Subsequently, another of the teaching strategies called, everyday expressions by mathematical reiterations, was used by teacher Rivaldo and teacher Cecília. This strategy consisted of the teacher asking questions to the student, in such a way that at the moment of giving the answers, he/she perceives that the student knows about the concept, but not in a formally mathematical way. Consequently, the following shows some of the moments where this teaching strategy was implemented:

Table 8. Everyday expressions through mathematical reiterations.

(O37) Cecilia: What is the relationship of the height with the base when you keep the area fixed? Do I double the height? Is that right?

(O38) Students: Yes.

(O39) Cecília: Ready! And here [it presents a sheet where it divides the height].

(O40) Student: to unfold.

(O41) Cecília: What is to unfold?

(O42) Student: Invert.

(O43) Cecília: And what is to invert?

(O44) Student: Divide.

(O45) Cecília: To unfold is to divide by 2 and to divide by 3 , how is it?

(O46) Student: unfolding three time I think [Laughing].

Source: Villota (2016)

The choice of this situation, where the use of the teaching strategy addressed by teacher Cecília is visualized and done randomly while teacher Rivaldo uses this strategy in an analogous way, but addressing the issue related to the location of rational numbers on the number line.

We observe that, in $(\mathrm{O} 37),(\mathrm{O} 40),(\mathrm{O} 43)$ and $(\mathrm{O} 45)$, through the questions generated by the teacher, the student responds according to his language, as shown in $(\mathrm{O} 40),(\mathrm{O} 42)$ and $(\mathrm{O} 43)$, using non-mathematical terms to express his response; but in the middle of that stimulation of questions asked by the teacher, he formally recognizes the mathematical concept, as it appears in (O44).

Another teaching strategy called, providing clues through the unfolding of the task, was used by teacher Cecília and teacher Rivaldo. That strategy consisted of, as the task was being explored, the teacher gave some clues to the students to propitiate and organize the arguments that were being constructed, as presented below:

Table 9. Providing clues through the unfolding of the task.

(O47) Cecília: Attention children! I will give a hint for the development of the task. I am observing, that, in the first question, they chose the height and the base, but at the time of placing the base they are not looking at any kind of size order; If you perceive that relationship, it will be interesting. But you must experiment, put the base in increasing order to see if you can get better results.

Source: Villota (2016)

In this situation, where teacher Cecília uses this teaching strategy, it was chosen in a random way since teacher Rivaldo used this strategy in an analogous way; that is, addressing the issue related to the location of rational numbers on the number line, maintaining the same structure presented in this situation.

In this way, we finish the "set of situations 2", which contains co-instructional teaching strategies, used during the development of the task, addressed by teachers Cecília, Rivaldo and Giovanna, described above. Thus, through each of the situations presented in this set of situations we identify the teaching strategies that were described and classified. Next we will present the set of situations 3, where we will find the teaching strategies that the teachers used as closure in the implementation of the different tasks. 
In this set of situations, we locate the teaching strategies that the teachers: Cecília, Rivaldo and Giovanna used to perform in confinement of the task; that is, the strategies used to close the implementation of the task.

The teaching strategy called, socialization of the task, was implemented by the teachers: Cecília, Rivaldo and Giovanna for the closure of the task. This strategy consisted of each of the teachers sharing the solution of the task to all their students. Below is a specific situation where this teaching strategy was implemented:

Table 10. Socialization of the task.

(O1) Cecília: I will share with you a possible way of doing the homework. Initially, the task will address the relationship between greatness. Then, we can define greatness as what people can measure. As, for example, the area, that measure must have a unit, with meter, centimeters, among others.

Source: Villota (2016)

This situation was selected in a random way, which shows the use of the teaching strategy addressed by teacher Cecília, since teachers Rivaldo and Giovanna used this strategy analogously. Therefore, they implemented it in a similar way, only changing the themes of the tasks; For example, teacher Rivaldo developed the task related to the location of rational numbers on the number line and teacher Giovanna developed the task related to the concept of percentage.

In fact, we observe in (O1) that teacher Cecília shares with her students a possible solution that the task may have. Consequently, this strategy opened doors for students to participate, ask and observe the resolution of the task; so the teachers used the teaching strategy called, clearing doubts, which consisted of the students expressing their different concerns that occurred in the exploration of the task. Next, we present the implementation of this strategy:

Table 11. Clear doubts.

(O3) Student: Teacher, that is, what can I do with the percentage?(,-eliminate)

can I calculate my final grade of all the disciplines?

(O4) Giovanna: Sure. You could use the percentage concept in many things, including the ones you are mentioning.

Source: Villota (2016)

This situation was chosen at random, where teacher Giovanna uses this teaching strategy; however, teachers Rivaldo and Giovanna used this strategy analogously; they implemented it in a similar way only that they changed the themes of the tasks; For example, teacher Rivaldo addressed the location of rational numbers on the number line and teacher Giovanna the concept of percentage.

Thus, we observe that in (O3) and (O4), students' participation was generated thanks to the strategy of "socialization of the task", and, that is where they asked the teacher their concerns in order to be solved.

Finally, we closed this set of situations (3), which contains the post-instructional teaching strategies used by all teachers, which were identified, described and classified.

Thus, through the three (3) sets of situations, we have presented all the teaching strategies used by teachers: Cecilia, Giovanna and Rivaldo in the implementation of the respective tasks; which were identified, described and classified in each of the sets. Well, in the next section, we will discuss the presented data.

\section{Discussion of the Data and Final Considerations}

In this article, the objective is to identify and describe the teaching strategies used by teachers in the implementation of mathematical tasks; through observation and interviews with teachers: Cecília, Rivaldo and Giovanna, who participated in this study. The observation helped us to identify the teaching strategies, serving as a support to perform the analysis of them, complementing the interviews as part of the process.

In this way, through the three sets of situations mentioned in the previous section, we present the different teaching strategies used by teachers: Cecília, Rivaldo and Giovanna, which were identified and described, each of them in specific situations. Through the three sets of situations, we started within the same process of identification and description of teaching strategies, the classification into the following categories: Pre-instructional, co- 
instructional and post-instructional, proposed by Díaz and Hernández (2010).

Within the pre-instructional strategies we locate all those opening strategies that teachers used before implementing the task, which were the following: Organization of students in small groups, state the objective of the task and shared reading of the task. This set of strategies strengthened the beginning of the development of the task; since they motivated, informed, guided and encouraged the students to explore the proposed task, as the teachers say:

Cecilia: "This set of strategies has the intention of attracting the attention of the student so that he explores the task, for example, the organization in small groups was important for me because I believe that the exchange of knowledge among classmates helps to solve the task. Meanwhile, stating the objective and reading the task was an invitation to get involved." (Interview, 12/19/2014).

Rivaldo: "These types of strategies provide the motivation of the student to develop the task, because I think it is in that initial part where you can feel restless to explore the task." The truth, for me, this strategy invite the student to manipulate the task, to feel the desire to do it "(Interview, 04/12/2014).

Giovanna: "This set of strategies practically opened the task, that is, it was at that moment that I applied each strategy to motivate the student to explore the task" (Interview, 12/13/2014).

The implementation of this set of teaching strategies is important since many times the student at the time of facing the task fear failure, as argued by Dweck and Elliot (1983) cited by Tapia (2005, p.4):

"... the student, when faced with a task, focuses above all on the possibility of failing instead of accepting it as a challenge and asking himself how he can do it, focusing on the results rather than the process that allows him to achieve them and considers the mistakes as failures and not as occasions from which it is possible to learn ".

Therefore, the set of pre-instructional teaching strategies served as mediating elements in the process of opening the mathematical task, motivating, inviting and guiding the students, from the beginning of the implementation of the task, with the intention to generate among them an excellent environment for the development of it.

On the other hand, the set of co-instructional teaching strategies were used during the task. In addition, this set of teaching strategies has a wide variety of strategies such as: Use of alternating questions, promote interaction between students, analogies related to daily life, legitimize the answers presented by students, everyday expressions through mathematical reiterations, provide clues through the task, daily expressions through mathematical reiterations.

However, it is important to clarify that this set of teaching strategies was not necessarily used by all the teachers, since some of them were hardly used by two teachers. At this point, the use of these strategies depended in large part on each of the teacher's methodologies, as they say:

Rivaldo: "I fully believe that the implementation of strategies depends on the methodology of the teacher, since it is he who, through this methodology, is looking for the right strategies to be used. For example, I really like using those strategies so the student understands what he is doing, so I try to relate those mathematical contexts to his everyday life "(Interview, 12/4/2014).

Cecília: "The methodology of the teacher influences the implementation of strategies. But, look, the methodology does not have to be fixed, it can change all the time. I always like to experiment, investigate and try to observe any activity that I have to do, because when I use strategies for my students, I try to do the same to construct the concepts "(Interview, 12/19/2014).

Giovanna: "Individually, the teacher's methodology made him use the strategies that he thinks it can help the learning of students, in our case, the development of the task" (Interview, 12/13/2014).

In this way, under the considerations of the teachers, we can see that teaching strategies depend in large part on the teacher's methodology. However, teacher Cecília states that this methodology should not be fixed, as she changes it as she experiences other elements, in order to strengthen students' learning; that is, the methodology must be renewable day by day with each of the experiences lived.

In this set of teaching strategies, the teachers: Cecília, Rivaldo and Giovanna, state that a large part of them were implemented thanks to the influence they have had with the experience of being part of the OME group, confessing that these strategies have totally changed their pedagogical practices, as stated below:

Giovanna: "I, like every math teacher, like to ask questions that I already have the answer. Students often ask questions and you answer. After I joined the OME, we started to educate in terms of not responding to the students; and the fact that they interact among them, builds knowledge. So the fact that I ask them and that they build the 
response among them in a discussion is what the task looks for "(Interview, 12/13/2014).

Rivaldo: "I think every teacher has strategies to try to help in the student's learning process, but knowing how to use them properly is complicated! And more in the development of the task. Fortunately, in my career as a professional, I had the opportunity to meet the OME group and it was from that group that I learned to (eliminate- how) listen to the students and I try to implement the strategies in the classroom" (Interview, 12/4/2014).

Cecilia: "Strategies are always in the hands of the teacher, but adapting them in the context where they are going to implement them is a very careful process. I, as a teacher, want the best for my students so I think the teacher must learn to educate himself. I, for example, am in this process, and I totally believe that the OME group has helped me, because it often happens that in the development of the task a strategy is implemented and we do not know why, what was the intention." (Interview, 12/13/2014)

Indeed, we can observe that each of the teachers recognize the great influence that the collaborative group OME (Observatory of Mathematic Education) has had at the time of implementing different co-instructional teaching strategies; for example, the interaction among students or the use of alternate questions, were teaching strategies, where the student is recognized as the center of the development of the mathematical task; that is, the main author.

Therefore, the co-instructional teaching strategies implemented by the teachers had a great influence from the OME group; thus, this experience has undoubtedly marked them in their professional and academic trajectory, adapting each of them, especially the teaching strategies, in their pedagogical practice.

Another of the sets of teaching strategies are the ones called post-instructional, used by teachers: Cecília, Rivaldo and Giovanna after the development of the task. In this set, we find strategies such as: Socialization of the task and clear doubts, both are closely related, since it was through the socialization of the task that the students expressed their different doubts about the development of it.

In this way, the socialization of the task becomes interesting as the students express their concerns, makes contributions, show other solutions or finally participate in the task, as stated by teacher Cecília:

"The socialization of the task is rich as the students participate in the development that is presented, because that is where they have the opportunity to ask questions and compare their answers" (Interview, 12/19/2014).

The socialization of the task was important for the students since the objective of developing the task among all was to observe, share, visualize and clear the doubts that several of them had had during the exploration of the task.

Finally, as a conclusion, the teachers who participated in this research used a great variety of teaching strategies which were identified through situations helping us as supports to describe and categorize them through three sets of situations. Each of the teaching strategies used by the teachers was not necessarily implemented by all since we had different situations where the teaching strategies are only used by two of them.

In this way, the teaching strategies used by the teachers were classified taking into account the categories: Preinstructional, co-instructional and post-instructional proposed by Díaz and Hernández (2010), with the purpose of structuring them and giving them a certain order at the time of being used and presented by the teachers in the process of the implementation of the task. However, it is important to highlight that some teaching strategies categorized within the set of pre-instructional strategies may also belong to the set of co-instructional strategies and / or at the same time post-instructional strategies; for example, state the purpose of the task, or perform the shared reading of the task are strategies that the teacher could use during or after the development of the task. Analogously, the same would happen with co-instructional and pre-instructional.

It should also be mentioned that the implementation of the strategies is not a recipe book, where the teacher can choose one of the teaching strategies mentioned above and use it without first making an adequate study of it; that is, there is no perfect or fixed teaching strategy for each of the learning situations. However, as Cabral (2013) states, these cookbooks take on value when they are used as "pedagogical recipes"; that is, similar to a culinary recipe that instead of producing a food that satisfies the biological needs of the human being, is to try to obtain a teaching strategy that is used to help the student obtain a certain level of knowledge.

However, there is a great variety of teaching strategies used by teachers: Cecília, Rivaldo and Giovanna, which depended on their methodology at the time they were implemented, although several of them were used by teachers in a similar way, but this does not indicate that the methodology used by each teacher was not unique. However, it is important to highlight that this methodology is not fixed, because it is constantly changing as circumstances change. 


\subsection{Perspectives}

The identification and description of teaching strategies used by mathematic teachers in task implementation, initially leads us to expand the set of such strategies respecting the methodology of the teacher; trying that the strategies identified, described and classified in this study are part of that methodology, with the purpose of contributing to the pedagogical practice of the teacher and therefore to the students' learning.

Thus, this study, by expanding the teaching strategies used by teachers, intends to propose strategies that help to restructure students' prior conceptions of scientific knowledge; as Carmo et al. (2010) cited by Ruppenthal and Chitolina (2015) there are few investigations in this regard.

In this way, it is interesting to be able to show the teacher that there are teaching strategies that can be implemented within his pedagogical practice. Therefore, there are teachers who use teaching strategies where the construction of the different concepts addressed in the tasks is not their focus, which limits the student to explore the different concepts submerged in the proposed tasks.

This research will help us to deepen the importance of the activities developed by the teacher during the implementation of teaching strategies, in terms of the development of mathematical tasks; to know why teachers use those teaching strategies presented in this study.

\section{References}

Anijovich, R., \& Mora, Y. S. (2009). Estrategias de enseñanza: Otra mirada al quehacer en el aula. Buenos Aires (Argentina): AIQUE.

Brum-De-Paula, M. R. Y S.bG. Espinar (2002). Coleta, transcrição e análise de produções orais. Letras, 1(21), 113.

Cabral, J. (2013). As recetas pedagógicas e o ensino da Matemática. Correios dos Açores: ensino/matemática. 14 . Recuperado de http://repositorio.uac.pt/handle/10400.3/2545.

Camilloni, A. (1998). Sobre la programación de la enseñanza de las ciencias sociales", en A.A.V.V. Didáctica de las Ciencias Sociales II, Buenos Aires: Paidós. En: Anijovich, R. y S. Mora (2009). Estrategias de enseñanza: Otra mirada al quehacer en el aula. Buenos Aires (Argentina): AIQUE.

Charmaz, K. (2009). A construção da teoria fundamentada: guia prático para análise qualitativa. Porto Alegre: Artmed.

Costa, O. W. (2015). A participação de professores de matemática e análise de materiais curriculares elaborados em um trabalho colaborativo. Dissertação de mestrado em educação: Universidade Estadual De Feira De Santana. A participação de professores na elaboração de tarefas matemáticas em um trabalho colaborativo. (pp. 42-72). Feira de Santana.

Creswell, J. W. (2007). Projeto de pesquisa: métodos qualitativo, quantitativo e misto. Porto Alegre: Artmed.

Denzin, N. K., \& Lincoln, Y. S.Y. (2005). Introduction: the discipline and practice of qualitative research. N.K. Denzin y Y.S. Lincoln (Eds.). Handbook of qualitative research. (pp. 1-32). Sage: Thousand Oaks.

Díaz B. F., \& Hernández, Y. G. (2010). Estrategias docentes para un aprendizaje significativo. México: McGRAW-HILL.

Gonzáles, P. S. (2009). Dominio de contenidos y estrategias de enseñanza de la matemática: Lecciones de un acompañamiento. Ciencia y sociedad, XXXIV(4), 516-577. Recuperado de http://www.redalyc.org/articulo.oa?id=87014516003

Kohler, J. (2005). Importancia de las Estrategias de Enseñanza y el Plan Curricular. Liberabit Revista de Psicología, 11(11), 25-34. Recuperado de http://redalyc.uaemex.mx/pdf/686/68601104.pdf

Quintero, J. (2008). Estrategias docentes como práctica de la teoría pedagógica. CONHISREMI, Revista Universitaria de Investigación y Diálogo Académico, 4(3), 23- 38.

Reitano, P. (2006). The value of video stimulated recall in reflective teaching practices. (ACSPRI) Social Science Methodology Conference. Paper presented at the Australian Consortium for Social and Political Research, New South Wales. (pp. 1-12). Recuperado de http://doi.org/pes:5074

Ruppenthal, R., \& Chitolina, E. M. R. (2015). A contextualização e as atividades práticas como estratégias no ensino do sistema respiratório para alunos do ensino fundamental. Revista Electrónica de Enseñanza de las Ciencias, 14(2), 200-222. Recuperado de http://www.saum.uvigo.es/reec

Tapia, J. A. (2005). Motivación para el aprendizaje: la perspectiva de los alumnos. Ministerio de Educación y 
Ciencias. La orientación escolar en centros educativos. 209-242. Recuperado de https://www.uam.es/gruposinv/meva/publicaciones\%20jesus/capitulos_espanyol_jesus/2005_motivacion $\% 2$ 0para\%20el\%20aprendizaje\%20Perspectiva\%20alumnos.pdf

\section{Copyrights}

Copyright for this article is retained by the author(s), with first publication rights granted to the journal.

This is an open-access article distributed under the terms and conditions of the Creative Commons Attribution license (http://creativecommons.org/licenses/by/4.0/). 